\title{
ANALISIS PENGGUNAAN KONJUNGSI PADA BUKU TEKS CATATAN PERISTIWA SEJARAH INDONESIA SMA/MA KELAS X KARANGAN MATROJI, TERBITAN BUMI AKSARA, TAHUN 2014
}

\author{
Dinda Nurita \\ FKIP Universitas Batanghari \\ e-mail: dindanuritaa95@gmail.com
}

In education, a textbook is one of important components that should be understood by students or teachers. That is why students must have an understanding in reading textbook. Conjunction is one of important aspects in the textbook. The level of students achievement in reading are influenced by the use of conjunction. Indeed this is related with students daily activity in studying and learning because it is directly linked with education world.

This paper is aimed at analyzing (1) the types of conjunction in the textbook Catatan Peristiwa Sejarah Indonesia SMA/MA class X by Matroji, published by Bumi Aksara year 2014 dan (2) the function of the textbook Catatan Peristiwa Sejarah Indonesia SMA/MA class X by Matroji, published by Bumi Aksara year 2014. This research is a relevance library study. The data is taken by documentation technique. The result of this research shows (1) the types of conjunction in the textbook Catatan Peristiwa Sejarah Indonesia SMA/MA class X by Matroji, published by Bumi Aksara year 2014.

Key Words: Conjunction, use, textbook

PENDAHULUAN

Permendiknas Nomor 2 tahun

2008 Pasal 1 menjelaskan bahwa

"Buku teks adalah buku acuan wajib untuk digunakan di satuan pendidikan dasar dan menengah atau perguruan tinggi yang memuat materi pembelajaran dalam rangka peningkatan keimanan, ketakwaan, akhlak mulia, dan kepribadian, penguasaan ilmu pengetahuan dan teknologi, peningkatan kemampuan kinestis dan kesehatan yang disusun berdasarkan standar nasional pendidikan oleh Badan Standar Nasional Pendidikan (BNSP)" yang berarti BNSP sebagai penilai kelayakan buku teks yang berkaitan dengan kelayakan isi, bahasa, penyajian, dan kegrafikan atau tampilan buku teks pelajaran. Ini berarti penulisan buku teks harus dilakukan dengan sangat teliti baik huruf, kata, frasa, kalimat maupun unsur-unsur tersebut harus memiliki keserasian agar dapat dimengerti oleh pembaca.

$$
\text { Menurut Chair }
$$
morfologi merupakan salah satu kajian 
dari linguistik yang mempelajari bentuk-bentuk kata dan juga perubahan-perubahan yang terdapat di dalam sebuah kata. Salah satu contoh penggunaan morfologi yaitu pada saat membuat karya tulis, baik dalam bentuk ilmiah maupun non ilmiah. Pada kajian morfologi yang sering kita dapati didalam karya tulis yaitu berbagai jenis kelas kata, salah satunya adalah konjungsi. Dalam penulisan konjungsi atau kata penghubung juga merupakan salah satu hal yang perlu diperhatikan di dalam penulisan. Karena kurang beragamnya penggunaan konjungsi yang akan mempengaruhi bentuk wacana yang akan dibaca maka akan terjadi kesalahpahaman oleh pembaca, dan juga kurangnya penggunaan konjungsi akan membuat siswa kurang mengetahui bentuk konjungsi. Pada akhirnya pembaca tidak akan memperoleh pemahaman mengenai apa yang dibacanya.

Berkaitan dengan hal di atas. Salah satu hal yang perlu diperhatikan dalam pembelajaran yaitu bahan ajar. Bahan ajar yang paling banyak digunakan saat ini yaitu buku teks. Buku teks memegang peranan penting terhadap pembelajaran yang akan dilakukan oleh siswa dan buku teks juga dapat menjadi acuan terhadap pengajaran yang dilakukan oleh guru.

Selain itu, analisis penggunaan konjungsi pada buku teks sepengetahuan belum pernah dilakukan oleh mahasiswa Program Studi Pendidikan Bahasa dan Sastra Indonesia Fakultas Keguruan dan Ilmu Pendidikan (FKIP) Universitas Batanghari. Demikian juga, berdasarkan hasil observasi penulis pada tanggal 5 November 2016 di perpustakaan FKIP Universitas Batanghari dan perpustakaan FKIP Universitas Jambi, tidak terdapat penelitian terkait dengan analisis konjungsi pada buku teks khususnya buku teks Catatan Peristiwa Sejarah Indonesia karangan Matroji, terbitan Bumi Aksara tahun 2014. Oleh sebab itu penulis menjadi sangat tertarik untuk mengkaji penggunaan konjungsi beserta bentuknya pada buku teks sejarah ini.

\section{METODOLOGI PENELITIAN}

Artikel ini termasuk penelitian dokumentasi dan studi literatur. Hasan (2002:11) mengatakan bahwa "Penelitian kepustakaan adalah penelitian yang dilaksanakan dengan 
menggunakan literature (kepustakaan), baik berupa buku, catatan maupun hasil laporan penelitian dari penelitian terdahulu". Lalu Hasan (2002:87) mengemukakan bahwa studi dokumentasi adalah teknik pengumpulan data yang tidak langsung ditunjukkan pada sebah penelitian, namun melalui dokumen". Dokumen yang dapat digunakan pada penelitian ini dapat juga berupa buku harian, surat pribadi, laporan, notulen rapat, catatan khusus, dan juga dokumen lainnya.

\section{HASIL DAN PEMBAHASAN}

Berdasarkan hasil penelitian dapat disimpulkan bahwa bentuk dan fungsi konjungsi ini tergambar dalam beberapa kutipan yang mencakup 8 bentuk konjungsi subordinatif.

1. Berdasarkan waktu yaitu konjungsi sehingga, setelah, sebelum, ketika, sejak, selama dan sampai.

2. Berdasarkan syarat yaitu konjungsi jika.

3. Berdasarkan konsesif yaitu konjungsi walaupun dan meskipun.

4. Berdasarkan kemiripan yaitu konjungsi sebagai dan seperti.
5. Berdasarkan penyebab yaitu konjungsi karena, oleh karena dan sebab.

6. Berdasarkan akibat yaitu konjungsi sehingga dan sampai.

7. Berdasarkan penjelasan yaitu konjungsi bahwa. Dan

8. Berdasarkan cara yaitu konjungsi dengan.

Bentuk konjungsi yang paling banyak terdapat dalam buku teks Catatan Peristiwa Sejarah Indonesia SMA/MA kelas X, karangan Matroji, terbitan Bumi Aksara tahun 2014 yaitu bentuk konjungsi subordinatif berdasarkan cara yaitu konjungsi dengan, dan yang paling sedikit digunakan yaitu bentuk konjungsi berdasarkan konsesif yaitu konjungsi walaupun.

Jenis fungsi konjungsi yang terdapat di dalam analisis ini yaitu menghubungkan klausa dengan klausa, klausa dengan frasa, klausa dengan kata dan kalimat dengan kalimat yang di dapat dari analisis jenis konjungsi. Fungsi konjungsi banyak digunakan yaitu yang menghubungkan klausa dengan klausa dan yang paling sedikit yaitu fungsi konjungsi yang menghubungkan klausa dengan kata. 
Dari hasil penelitian yang telah di jabarkan di atas berdasarkan jumlahnya. Maka pada bagian ini akan mengupas lebih dalam mengenai analisis dari bentuk dan juga fungsi konjungsi subordinatif.

\section{Pembahasan Bentuk Konjungsi}

Pada bentuk konjungsi terdapat 8 jenis konjungsi yang di temui di dalam penelitian ini. Berikut pembahasannya:

\section{Bentuk Penggunaan Konjungsi}

Subordinatif Berdasarkan Waktu pada BukuTeks Catatan Peristiwa

Sejarah Indonesia SMA/MA Kelas

X, Karangan Matroji, Terbitan

Bumi Aksara Tahun 2014.

\begin{tabular}{|l|l|l|}
\hline No & \multicolumn{1}{|c|}{ Kutipan } & Ket \\
\hline 1 & $\begin{array}{l}\text { Peristiwa-peristiwa } \\
\text { penting terjadi selama } \\
\text { kerajaan itu berdiri. }\end{array}$ & L78 \\
2 & $\begin{array}{l}\text { Manusia purba adalah } \\
\text { manusia yang hidup } \\
\text { jauh sebelum tulisan } \\
\text { ditemukan. L148 } \\
\text { Bekal-bekal kubur dan } \\
\text { wadah mayat } \\
\text { disesuaikan dengan } \\
\text { kedudukannya ketika } \\
\text { masih hidup. } \\
\text { Ajaran agama Buddha } \\
\text { mulai ada di Indonesia } \\
\text { di perkirakan sejak } \\
\text { abad ke-2 } \\
\text { Rakai Panangkaran } \\
\text { memerintah setelah } \\
\text { Sanjaya }\end{array}$ & L423 \\
\hline
\end{tabular}

Pada kutipan yang terdapat di dalam tabel, merupakan variasi konjungsi subordinatif berdasarkan waktu yang di temukan dalam buku teks. Konjungsi subordinatif selama, sebelum, ketika, sejak dan setelah pada tabel dikatakan sebagai konjungsi subordinatif berdasarkan waktu. Karena semua kutipan tersebut berfungsi untuk menjelaskan suatu hubungan waktu ataupun peristiwaperistiwa yang telah terjadi.

\section{Bentuk Penggunaan Konjungsi}

Subordinatif Berdasarkan Syarat

pada Buku Teks Catatan Peristiwa

Sejarah Indonesia SMA/MA Kelas

X, Karangan Matroji, Terbitan

Bumi Aksara Tahun 2014.

\begin{tabular}{|c|c|c|}
\hline No & Kutipan & Ket \\
\hline 1 & $\begin{array}{lr}\text { Interpretasi } & \text { hanya } \\
\text { digunakan sebagai uatu } \\
\text { metode } \\
\text { dibutuhkan. }\end{array}$ & L38 \\
\hline 2 & $\begin{array}{l}\text { Tujuan dari kedua } \\
\text { motif itu tidak akan } \\
\text { tercapai jika pengaruh } \\
\text { objektivisme yang } \\
\text { tidak dapat diterapkan. }\end{array}$ & L55 \\
\hline 3 & $\begin{array}{lr}\text { Ada } & \text { beberapa } \\
\text { interpretasi } & \text { yang } \\
\text { memerlukan sejumlah } \\
\text { hipotetsis yang bersifat } \\
\text { membantu jika } \\
\text { sejarawan ingin bebas } \\
\text { dari kesalahan oleh } \\
\text { laporan. }\end{array}$ & L64 \\
\hline
\end{tabular}


Pada kutipan yang terdapat di dalam tabel terdapat 3 buah kutipan yang mewakili konjungsi subordinatif berdasarkan syarat yang terdapat di dalam buku teks. Hanya terdapat satu jenis variasi yaitu jika. Konjungsi subordinatif jika dikatakan sebagai konjungsi subordinatif berdasarkan syarat karena menyatakan mengenai suatu hal yang akan terjadi setelah syarat-syarat tersebut dilakukan.

Bentuk Penggunaan Konjungsi Subordinatif Berdasarkan Konsesif atau Pembenaran pada Buku Teks Catatan Peristiwa Sejarah Indonesia SMA/MA Kelas X, Karangan Matroji, Terbitan Bumi Aksara

Tahun 2014.

\begin{tabular}{|c|c|c|}
\hline No & Kutipan & Ket \\
\hline 1 & $\begin{array}{l}\text { Kenyataannya ini } \\
\text { dapat memperkaya } \\
\text { dunia } \\
\text { histografiterutama } \\
\text { histografi di } \\
\text { Indonesia. Walaupun } \\
\text { pendekatan terhadap } \\
\text { teori dan hukum ilmu } \\
\text { sosial penting dalam } \\
\text { penulisan sejarah. }\end{array}$ & L15 \\
\hline 2 & $\begin{array}{l}\text { Pengenalan ajaran dan } \\
\text { nilai-nilai Islam nelum } \\
\text { tentu memperoleh } \\
\text { tanggapan } \\
\text { pengaruh saat } \\
\text { Buddha masi kuat. } \\
\text { Meskipun demikian, }\end{array}$ & L622 \\
\hline
\end{tabular}

\begin{tabular}{|l|lr|l|}
\hline 3 & $\begin{array}{l}\text { para pedagang } \\
\text { tetap Islam } \\
\text { berdakwah,... }\end{array}$ & L708 \\
Oktif & \\
$\begin{array}{l}\text { Oleh sebab reskipun itu, } \\
\text { memerintah sanya } \\
\text { empat tahun,... }\end{array}$ & selama & \\
\hline
\end{tabular}

Pada tabel di atas terdapat dua variasi pada konjungsi jenis ini yaitu walaupun dan meskipun. Konjungsi subordinatif tersebut dikatakan sebagai konjungsi subordinatif konsesif atau pembenaran. Karena berfungsi melakukan pembenaran terhadap dua bagian kalimat yang sederajat.

\section{Bentuk Penggunaan Konjungsi}

Subordinatif Berdasarkan

Kemiripan pada Buku Teks Catatan

Peristiwa Sejarah Indonesia

SMA/MA Kelas X, Karangan

Matroji, Terbitan Bumi Aksara

Tahun 2014.

\begin{tabular}{|c|c|c|}
\hline No & Kutipan & Ket \\
\hline 1 & $\begin{array}{lr}\text { Karena } & \text { histografi } \\
\text { tersebut } & \text { seperti } \\
\text { penulisan } & \text { sejarah } \\
\text { yang umum, sama } \\
\text { dan nomotetis. }\end{array}$ & L17 \\
\hline 2 & $\begin{array}{l}\text { Pendekatan terhadap } \\
\text { ilmu-ilmu sosial } \\
\text { seperti antropologi, } \\
\text { psikologi, ekonomi, } \\
\text { sosiologi, geografi } \\
\text { dan demografi. }\end{array}$ & L12 \\
\hline 3 & Jika suatu objek & $\mathrm{L} 40$ \\
\hline
\end{tabular}

Analisis Penggunaan Konjungsi pada Buku Teks Catatan Peristiwa Sejarah Indonesia SM A/M A Kelas X Karangan M atroji, Terbitan Bumi Aksara, Tahun 2014 


\begin{tabular}{|l|lr|l|}
\hline $\begin{array}{l}\text { seperti karya seni } \\
\text { cukup } \\
\text { maknanya, }\end{array}$ & jelas & \\
\hline
\end{tabular}

Pada tabel di atas terdapat 3 kutipan dan hanya memiliki satu variasi yang di dapatkan dari hasil penelitian yaitu seperti. Konjungsi subordinatif seperti dapat dikatakan sebagai konjungsi subordinatif berdasarkan kemiripan. Karena konjungsi tersebut menghubungkan antara bagian satu dengan bagian lainnya sehingga bisa dikatakan mirip ataupun serupa.

Bentuk Penggunaan Konjungsi

Subordinatif Berdasarkan

Penyebab pada Buku Teks Catatan

Peristiwa Sejarah Indonesia

SMA/MA Kelas X, Karangan

Matroji, Terbitan Bumi Aksara

Tahun 2014.

\begin{tabular}{|l|l|l|}
\hline No & \multicolumn{1}{|c|}{ Kutipan } & Ket \\
\hline 1 & $\begin{array}{l}\text { Oleh karena itu, } \\
\text { diperlukan metode } \\
\text { yang tepat dalam } \\
\text { melakukan } \\
\text { pendekatan terhadap } \\
\text { teori dan hukum ilmu } \\
\text { sosial dalam penulisan } \\
\text { sejarah. }\end{array}$ & \\
& $\begin{array}{l}\text { Alat-alat dari batu } \\
\text { yang digunakan pada } \\
\text { zaman batu tua masi } \\
\text { sangat kasar, sebab } \\
\text { teknik pembuatannya }\end{array}$ & \\
\hline
\end{tabular}

\begin{tabular}{|l|l|l|}
\hline 3 & $\begin{array}{l}\text { masih sederhana. } \\
\text { Mungkin alat-alat itu } \\
\text { telah hancur karena } \\
\text { karat. }\end{array}$ & L235 \\
\hline
\end{tabular}

Pada tabel di atas terdapat 3 variasi dari konjungsi subordinatif berdasarkan penyebab. Konjungsi subordinatif pada tabel dikatakan sebagai konjungsi subordinatif berdasarkan penyebab. Karena konjungsi tersebut menjelaskan suatu peristiwa terjadi akibat suatu sebab tertentu.

Bentuk Penggunaan Konjungsi

Subordinatif Berdasarkan Akibat pada Buku Teks Catatan Peristiwa Sejarah Indonesia SMA/MA Kelas

X, Karangan Matroji, Terbitan

Bumi Aksara Tahun 2014.

\begin{tabular}{|c|c|c|}
\hline No & Kutipan & Ket \\
\hline 1 & \begin{tabular}{lr}
\multicolumn{2}{l}{ Peristiwa-peristiwa } \\
tersebut juga terus \\
bergerak sehingga \\
melahirkan & peristiwa \\
baru. &
\end{tabular} & L23 \\
\hline 2 & 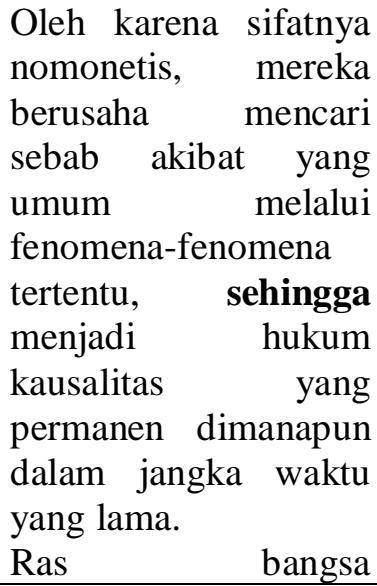 & L24 \\
\hline
\end{tabular}




\begin{tabular}{|l|lr|l|}
\hline 3 & $\begin{array}{l}\text { Mongoloid } \\
\text { Indonesia }\end{array}$ & sampai & L267 \\
& sekarang & baru & \\
ditemukan & di & Pulau & \\
Jawa. & & & \\
\hline
\end{tabular}

Pada tabel di atas terdapat 2 variasi yaitu sehingga dan sampai. Kedua konjungsi ini disebut dengan berdasarkan akibat. Karena konjungsi tersebut menyatakan bahwa suatu peristiwa terjadi akibat peristiwa yang lainnya. Sehingga konjungsi tersebut termasuk kedalam golongan konjungsi subordinatif berdasarkan akibat.

Bentuk Penggunaan Konjungsi

$$
\text { Subordinatif Berdasarkan }
$$

Penjelasan pada Buku Teks Catatan

Peristiwa Sejarah Indonesia

SMA/MA Kelas X, Karangan

Matroji, Terbitan Bumi Aksara

Tahun 2014.

\begin{tabular}{|c|c|c|}
\hline No & Kutipan & Ket \\
\hline 1 & $\begin{array}{l}\text { Namun, terkadang } \\
\text { sudut pandang } \\
\text { sejarawan meyakini } \\
\text { bahwa ia telah } \\
\text { mengintrepretasi } \\
\text { masalah sejarah } \\
\text { secara objektif. }\end{array}$ & L58 \\
\hline 2 & $\begin{array}{lr}\text { Berdasarkan } & \text { contoh } \\
\text { tersebut dapat kita } \\
\text { ketahui } & \text { bahwa } \\
\text { keberlanjutan } & \text { terjadi } \\
\text { bila } & \text { suatu } \\
\text { masyarakat hanya } & \text { melakukan adopsi } \\
\text { lembaga lama. }\end{array}$ & L101 \\
\hline
\end{tabular}

\begin{tabular}{|l|l|l|}
\hline 3 & Berdasarkan & L190 \\
& penemuan alat-alat & \\
& paleothikum dapat & \\
& disimpulkan bahwa & \\
& manusia pendukung & \\
zaman batu. & \\
\hline
\end{tabular}

Pada tabel di atas terdapat satu variasi yaitu bahwa. Konjungsi ini termasuk dalam konjungsi subordinatif berdasarkan penjelasan. Karena konjungsi ini berfungsi sebagai penghubung dari penjelasan mengenai suatu peristiwa yang terjadi.

\section{Bentuk Penggunaan Konjungsi}

Subordinatif Berdasarkan Cara

pada Buku Teks Catatan Peristiwa

Sejarah Indonesia SMA/MA Kelas

X, Karangan Matroji, Terbitan

Bumi Aksara Tahun 2014.

\begin{tabular}{|l|lr|l|}
\hline No & \multicolumn{2}{|c|}{ Kutipan } & Ket \\
\hline 1 & Sejarah & sebagai & L5 \\
& ilmu & mempunyai & \\
& metode & sendiri & \\
& yang & harus & \\
& digunakan & oleh & \\
& sejarawan & dalam & \\
& menulis & sejarah. \\
& Dengan & \\
& menggunakan & \\
& metode & tersebut \\
& sejarawan & mampu \\
& merekonstruksi & \\
& sejarah & dengan & \\
& objektif. & \\
& Model & penulisan & L8 \\
& deskriptif & naratif \\
& adalah & melakukan \\
& penulisan & sejarah \\
& hanya dengan cara & \\
\hline
\end{tabular}




\begin{tabular}{|l|l|l|}
\hline 3 & $\begin{array}{l}\text { merangkai fakta } \\
\text { yang disusun secara } \\
\text { kronologis. }\end{array}$ & \\
& $\begin{array}{l}\text { Interpretasi yang } \\
\text { berlebihan dengan } \\
\text { menggunakan } \\
\text { pendekatan } \\
\text { multidimensional } \\
\text { juga } \\
\text { mengaburkan batas } \\
\text { antara fakta dan } \\
\text { fiksi dalam sejarah }\end{array}$ & \\
\hline
\end{tabular}

Pada tabel di atas terdapat satu variasi yaitu dengan. Konjungsi subordinatif dengan dikatakan sebagai konjungsi subordinatif berdasarkan cara. Karena menyatakan mengenai tata cara dalam melakukan suatu hal.

\section{Pembahasan Fungsi Konjungsi}

Jenis fungsi konjungsi yang terdapat di dalam analisis ini yaitu menghubungkan klausa dengan klausa sebanyak 420 kutipan, klausa dengan frasa sebanyak 147 kutipan, klausa dengan kata 1 kutipan dan kalimat dengan kalimat sebanyak 168 kutipan.

Fungsi Penggunaan Konjungsi yang Menghubungkan Klausa dengan

Klausa pada Buku Teks Catatan

Peristiwa Sejarah Indonesia

\section{SMA/MA Kelas X, Karangan}

\section{Matroji, Terbitan Bumi Aksara}

\begin{tabular}{|c|c|c|}
\hline No & Kutipan & Ket \\
\hline 1 & $\begin{array}{l}\text { Peristiwa-peristiwa } \\
\text { penting terjadi selama } \\
\text { kerajaan itu berdiri. }\end{array}$ & L78 \\
\hline 2 & $\begin{array}{l}\text { Karena histografi } \\
\text { tersebut } \\
\text { penulisan sejarah yang } \\
\text { umum }\end{array}$ & L7 \\
\hline 3 & $\begin{array}{l}\text { Mereka berusaha } \\
\text { mencari sebab akibat } \\
\text { yang umum melalui } \\
\text { fenomena tertentu,... }\end{array}$ & L23 \\
\hline
\end{tabular}

Pada tabel di atas menunjukkan fungsi konjungsi yang menghubungkan klausa dengan klausa. Yaitu menghubungkan antara "Mereka berusaha mencari..." dengan klausa "akibat yang umum melalui fenomena tertentu,...". Sehingga menjadi satu kalimat yang padu.

Fungsi Penggunaan Konjungsi yang Menghubungkan Klausa dengan

Frasa pada Buku Teks Catatan Peristiwa Sejarah Indonesia

SMA/MA Kelas X, Karangan

Matroji, Terbitan Bumi Aksara

Tahun 2014.

\section{Tahun 2014.}




\begin{tabular}{|l|l|l|}
\hline No & \multicolumn{1}{|c|}{ Kutipan } & Ket \\
\hline 1 & $\begin{array}{l}\text { Manusia purba } \\
\text { adalah manusia yang } \\
\text { hidup jauh sebelum } \\
\text { tulisan ditemukan. }\end{array}$ & L148 \\
2 & $\begin{array}{l}\text { Banyak hasil karya } \\
\text { Sartono yang terus } \\
\text { dipakai sampai saat } \\
\text { ini L27 } \\
3\end{array}$ & $\begin{array}{l}\text { Interpretasi hanya } \\
\text { digunakan sebagai } \\
\text { suatu metode }\end{array}$ \\
L37
\end{tabular}

Pada tabel di atas menunjukkan fungsi konjungsi yaitu menghubungkan antara klausa dengan frasa. Yaitu menghubungkan antara klausa "Banyak hasil karya Sartono yang terus dipakai" dengan frasa "saat ini”. Sehingga hubungan antara keduanya dapat menjadikan kalimat yang padu.

\section{Fungsi Penggunaan Konjungsi yang}

Menghubungkan Klausa dengan

Kata pada Buku Teks Catatan

Peristiwa Sejarah Indonesia

SMA/MA Kelas X, Karangan

Matroji, Terbitan Bumi Aksara

Tahun 2014.

\begin{tabular}{|l|l|c|}
\hline No & \multicolumn{1}{|c|}{ Kutipan } & Ket \\
\hline 1 & $\begin{array}{l}\text { Rakai Panangkaran } \\
\text { memerintah setelah } \\
\text { Sanjaya... }\end{array}$ & L423 \\
\hline
\end{tabular}

Fungsi konjungsi pada tabel di atas menunjukkan hubungan antara klausa dengan kata. Yaitu klausa

"Rakai Panangkaran memerintah..."

dengan kata "Sanjaya”. Sehingga

menjadi kalimat yang padu. Fungsi

konjungsi pada jenis ini hanya

ditemukan satu kutipan.

Fungsi Penggunaan Konjungsi yang

Menghubungkan Kalimat dengan

Kalimat pada Buku Teks Catatan

Peristiwa Sejarah Indonesia

SMA/MA Kelas X, Karangan

Matroji, Terbitan Bumi Aksara

Tahun 2014.

\begin{tabular}{|c|c|c|}
\hline No & Kutipan & Ket \\
\hline 1 & $\begin{array}{lr}\text { Intepretasi } & \text { yang } \\
\text { berlebihan dengan } \\
\text { menggunakan } \\
\text { pendekatan } \\
\text { multidimensional juga } \\
\text { akan mengaburkan batas } \\
\text { antara fakta dan fiksi } \\
\text { dalam sejarah. Oleh } \\
\text { karena itu, diperlukan } \\
\text { metode yang tepat dalam } \\
\text { melakukan pendekatan } \\
\text { terhadap teori dan } \\
\text { hukum ilmu sosial } \\
\text { dalam penulisan sejarah. }\end{array}$ & L24 \\
\hline 2 & 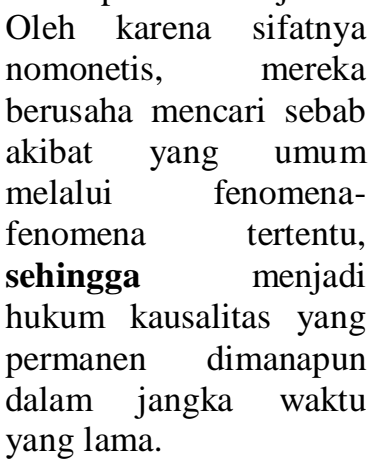 & L24 \\
\hline 3 & Urutan dan & $\mathrm{L} 48$ \\
\hline
\end{tabular}




\begin{tabular}{|c|}
\hline $\begin{array}{l}\text { keberlanjutan dalam } \\
\text { interpretasi maupun } \\
\text { eksplanasi menjadi hal } \\
\text { yang wajib di taati agar } \\
\text { tidak terjadi kesalahan- } \\
\text { kesalahan dalam } \\
\text { penulisan. Jika fakta } \\
\text { yang dirangkai tidak } \\
\text { berkelanjutan dan urutan } \\
\text { waktunya. }\end{array}$ \\
\hline
\end{tabular}

Fungsi konjungsi pada tabel yaitu menghubungkan kalimat dengan kalimat. Yaitu kalimat "Intepretasi yang berlebihan dengan menggunakan pendekatan multidimensional juga akan mengaburkan batas antara fakta dan fiksi dalam sejarah"dengan kalimat "diperlukan metode yang tepat dalam melakukan pendekatan terhadap teori dan hukum ilmu sosial dalam penulisan sejarah." sehingga menjadi wacana yang padu.

\section{KESIMPULAN DAN SARAN}

\section{Kesimpulan}

Bentuk konjungsi subordinatif yang didapat dari penelitian ini yaitu berdasarkan waktu yaitu konjungsi sehingga, setelah, sebelum, ketika, sejak, selama dan sampai. Berdasarkan syarat yaitu konjungsi jika. Berdasarkan konsesif yaitu konjungsi walaupun dan meskipun. Berdasarkan kemiripan yaitu konjungsi sebagai dan seperti. Berdasarkan penyebab yaitu konjungsi karena, oleh karena dan sebab. Berdasarkan akibat yaitu konjungsi sehingga dan sampai. Berdasarkan penjelasan yaitu konjungsi bahwa. Dan berdasarkan cara yaitu konjungsi dengan. Sedangkan untuk fungsi konjungsi subordinatif yaitu terdapat fungsi konjungsi yang menghubungkan klausa dengan klausa, fungsi konjungsi menghubungkan klausa dengan frasa, fungsi konjungsi menghubungkan klausa dengan kata dan fungsi konjungsi menghubungkan kalimat dengan kalimat. Bentuk konjungsi yang paling banyak terdapat dalam buku teks Catatan Peristiwa Sejarah Indonesia SMA/MA kelas X, karangan Matroji, terbitan Bumi Aksara tahun 2014 yaitu bentuk konjungsi subordinatif berdasarkan cara yaitu konjungsi dengan, dan yang paling sedikit digunakan yaitu bentuk konjungsi berdasarkan konsesif yaitu konjungsi walaupun. Fungsi konjungsi banyak digunakan yaitu yang menghubungkan klausa dengan klausa dan yang paling sedikit yaitu fungsi konjungsi yang menghubungkan klausa dengan kata. 
2. Saran

1. Disarankan akan di lanjutkan dengan penelitian lain yang berkaitan dengan bentuk dan fungsi konjungsi, namun di dalam bukubuku yang lainnya.

2. Disarankan bagi guru agar menjadikan kajian konjungsi ini sebagai bahan ajar, agar konjungsi ini dikuasai oleh siswa sehingga maksud yang akan disampaikan oleh penulis akan mampu dipahami oleh siswa sehingga memperoleh pemahaman yang baik.

\section{DAFTAR PUSTAKA}

Arikunto. 2006. Prosedur Penelitian Suatu Pendekatan Praktik. Jakarta: Rineka Cipta.

Aldi, dkk. 2003. Konjungsi. Jakarta: Balai Pustaka

Alwi, Hasan. 2005. Kamus Besar Bahasa Indonesia Edisi Ketiga. Jakarta: Balai Pustaka.

Chaer, Abdul. 2012. Linguistik Umum. Jakarta: Rineka Cipta.

Dardjowidjojo, Soenjono. 2000. Psikolinguistik. Jakarta: Yayasan Obor Indonesia.

Kridalaksana, Harimurti. 2007. Pembentukan Kata Dalam
Bahasa Indonesia. Jakarta: PT Gramedia Pustaka Utama.

Keraf, Gorys. 1984. Tata Bahasa Indonesia. Endo-Flores: Nusa Indah.

Matroji. 2014. Catatan Peristiwa Sejarah Indonesia. Jakarta: Bumi Aksara.

Mahsun. 1990. Metode Penelitian Bahasa. Yogyakarta: PT Raya Grafindo Persada.

Muda, Ahmad. 2006. Kamus Lengkap Bahasa Indonesia. Jakarta: Reality Publisher.

Muhammad. 2011. Metode Penelitian Bahasa.Yogyakarta: Ar-Ruzz Media.

Muslich, Masnur. 2003. Fonologi Bahasa Indonesia. Jakarta: Bumi Aksara.

Pateda, Mansoer. 2011. Linguistik (Sebuah Pengantar). Bandung: Angkasa.

Ramlan. 1990. Tata Bahasa Indonesia Penggolongan Kata. Yogyakarta: Andi Ofset.

Sugiyono. 2013. Metode Penelitian Kuantitatif Kualitatif dan $R \&$ $D$. Bandung: Alfabeta.

Siswantoro. 2014. Metode Penelitian Sastra. Yogyakarta: Pustaka Pelajar. 
Tirtawijaya, Totong. 1989. Morfologi

Bahasa Indonesia. Surabaya. Bumi Aksara.

Waridah, Ernawati. 2014. Ejaan yang Disempurnakan dan Seputar Kebahasa Indoneisaan.

Bandung: Ruang Kata

https://googleweblight.com/?lite url= https://ayyubarmansyah.word press.com (diakses pada tanggal 1 Januari 2017)

http://www.permendiknas.go.id/undan g-undang-tentang-buku-teksdisekolah/s.html?m=1 (diakses pada tanggal 5 Maret 2017) http;/googleweblight.com/lite_url=htt $\mathrm{p}: / / \mathrm{www} \cdot$ belajarbahasaindone sia.com/contoh-katapenghubung-konjungsikoordinatif-subordinatif-dankorelatif/\&ei=xirKQCW\&lc= id-ID\&s $=m=687 \&$ host (diakses pada tanggal 10 maret 2017) 